\title{
ASSESSMENT OF RECYCLED CONCRETE AGGREGATE (RCA) USAGE IN CONCRETE
}

\author{
Tresor Ntaryamira ${ }^{1}$, Anthony Quansah ${ }^{2}$, Yunlian Zhang ${ }^{3}$ \\ ${ }^{l}$ MSc, Civil Engineering, Zhejiang University of Science and Technology, Zhejiang, China \\ ${ }^{2} \mathrm{MSc}$, Civil Engineering, Zhejiang University of Science and Technology, Zhejiang, China \\ ${ }^{3}$ Professor, Civil Engineering, Zhejiang University of Science and Technology, Zhejiang, China
}

\begin{abstract}
Recycling concrete is a significant step towards eco-friendly construction practices. The use of recycled concrete aggregates in new structures provides a sustainable development. Initially, recycling of demolition waste was first carried out after the Second World War in Germany and henceforth, there have been reduction in the quantity of construction and demolition waste; and at the same time, it lessened the depletion of natural resources by providing an alternative. There have been recorded cases of application of recycled aggregate(RA) in a large number of construction projects of many European, American, Russian and Asian countries. The test results of ductility and the stiffness of beams with RA are equal or higher than those with natural aggregate. However, concrete made with recycled concrete aggregates exhibits different engineering properties. This difference is mainly due to the attached mortar paste on recycled concrete particles. Recycled aggregates have been found to have high water absorption capacity, which affects various properties mainly mechanical performance of the resulting concrete mix. Based on previous research, this paper presents a comprehensive overview of the recycled concrete material characteristics and the effect of using recycled concrete material on the mechanical properties, the durability properties and structural performance of concrete so as to help relevant units and staffs in the practical work.
\end{abstract}

Keywords: - Recycling Concrete, Recycled Concrete Aggregates, Water Absorption, Attached Mortar, Mechanical Properties, Durability

\section{INTRODUCTION}

Population growth and rapid urbanization rate in developing countries has increased the construction of new living, working, sanitary and transportation infrastructures. Concrete is one of the most used construction material because it has a longer life, low maintenance cost and excellent performance. However, its production gives rise to the consumption of natural resources. According to the Freedonia Group study, the global demand for construction aggregates is expected to advance 51.7 billion metric tons in 2019, and China alone accounted for more than $50 \%$ of worldwide demand for all new aggregates during the period 2010-2015 [1]. Meanwhile, there is a high rate of construction and demolition (C\&D) waste produced yearly due to the demolition of old structures, natural disasters like earthquakes, avalanches, and tornadoes; human causes like war, bombing and structural failures. In China, C\&D activities generated over two billion tons of $C \& D$ waste in 2011 [2]. The disposal into landfills of these C\&D waste is an increasing concern throughout the world. The inappropriate disposal of $C \& D$ waste is an issue faced by many municipalities. It is responsible together with other factors for damages to landscapes and other damages to human safety and living beings. For instance, at the end 2015, a landslide happened at the Hongao construction waste dump, Shenzhen in China. It destroyed buildings and killed workers living in the nearby [3]. In excess of the disasters accompanied with improper disposal of demolition waste, there is also high negative impact on our environment's sustainability. Owing to its significant impact on the natural environment, there is a high requirement of environmental sustainability practices in our modern construction works and hence a proper management of C\&D is critical. The old concrete waste can be crushed, processed and reused as recycled concrete aggregates (RCA) in new concrete structures. This recycling contributes to a greater sustainability in the construction industry because it provides a solution to the problem of C\&D waste management and prevents the depletion of natural aggregates (NA) by providing alternative aggregates. Many countries are giving infrastructural laws relaxation for increasing the use of recycled aggregate.However, due to the lack of proper code and standard, many aspects need attention and handling during the design and the application of recycled concrete structures. In this review paper, the challenges of using RCA such as the attached old mortar paste, its high porosity, its high permeability and its high water absorption; and the effect of RCA on rheological properties of the fresh concrete mix, on the mechanical properties and long-term service of RCA concrete are presented.

\subsection{Habitual Sources of RCA}

Previous researches have showed that the concrete containing RCA obtained from high strength parent concrete exhibited better mechanical properties than that containing 
RCA made low strength concrete. For this reason, the source of RCA is very important and fair idea about the extraction site should be considered. The sites for extraction of RCA can be sites of razed buildings, bridges, sidewalks and roads after a period of time into their service life for purpose of replacement or landscape changes. Other sources of waste include natural disasters like earthquakes, avalanches, and tornadoes; human causes like war and bombing; and structural failures.

\subsection{Production and Quality of RCA}

The commonly recycling concrete process includes the demolition of the old structure into pieces small enough to be handled. Follows the removal of undesired items present in the original concrete. Finally, demolished concrete pieces undergo a series of screening, removal of contaminants, and crushing that result in RCA sized to meet particular grading requirements. Figure 1 shows a typical recycling process.

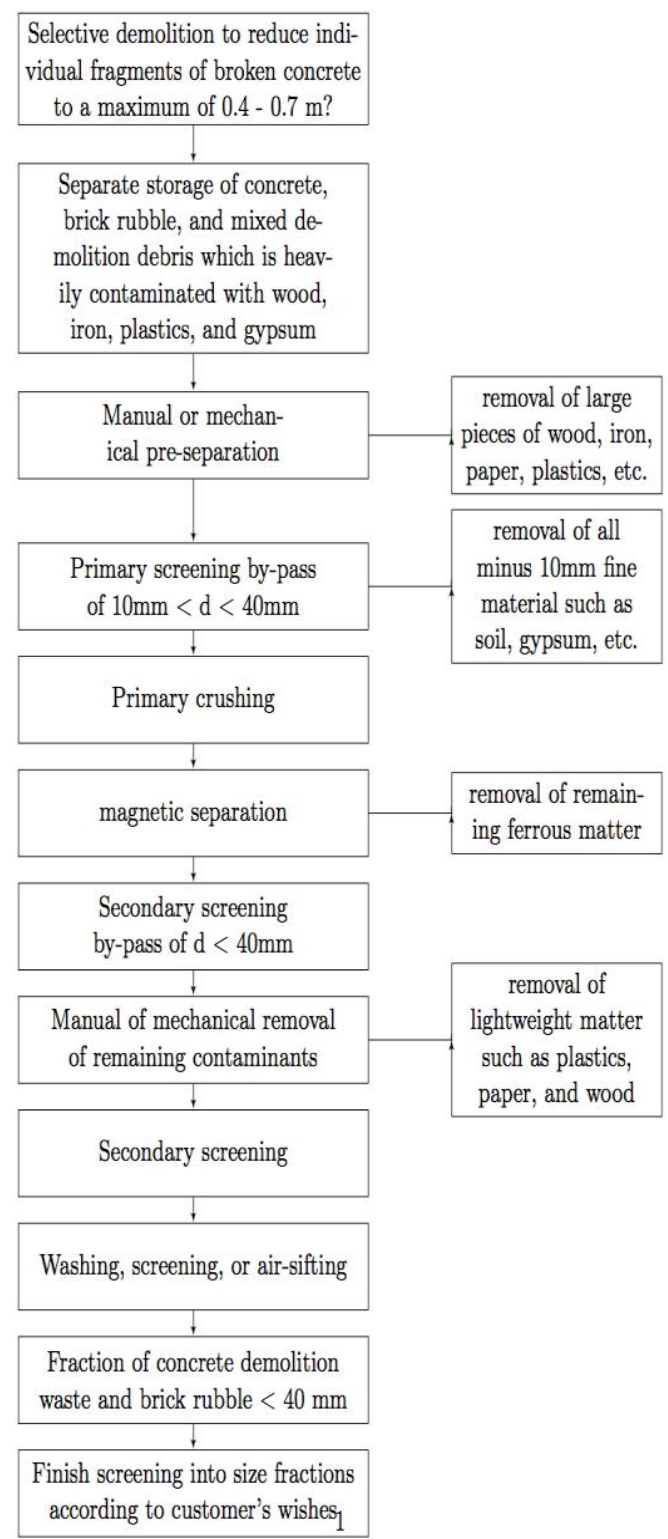

Fig -1:Typical recycling concrete process
The amount of adhered mortar paste (AMP) attached to the RCA greatly influences their quality. The quantity of AMP on the recycled aggregates particles depends on various factors such as the condition of the original concrete and crushing process. Findings have shown that when the steps of crushing procedures increase, the amount of AMP on RCA decreases [4]. The attached mortar is responsible for higher water absorption capacity, lower density, higher porosity and possible content of harmful substances of RCA compared with NA. Hence, it is crucial to control the amount of residual mortar present in RCA. Faced with this situation, numerous researchers have attempted to develop efficient methods to enhance the quality of RCA. Akbarnezhad et al. [5] introduced a microwave-assisted technique to improve the quality of RCA by removing a part of the attached residual mortar paste. This method makes use the difference in the electromagnetic properties of the adhered mortar and natural aggregates. Pepe et al. [6] used a rotating mill drum to process RCA. Aggregates collide each other while removing pieces of adhered mortar. The results showed that the autogenous cleaning method could reduce the water absorption capacity of RCA up to $50 \%$. Al-Bayati et al. [7] used different techniques to enhance the physical and morphological properties of RCA. They reported that heat treatment combined with short mechanical treatment exhibit the best performance. Besides, there has been much research about the RCA's surface treatment methods with acid. Acid can dissolve cement hydration products. Researchers used acid to remove AMP from RCA particles. Research results proved that the utilization of this technique reduces the water absorption of RCA and improve mechanical properties without of RCA concrete without adverse effect on the alkalinity of RCA concrete. The microstructure analysis of the treated RCA has demonstrated that their ITZs are less porous, denser and have connected microstructure. Also, there is a linear relationship between the amount of mortar loss with the increase of the molarity of acid.[8][9][10].

\section{PROBLEMS OF ADHERED MORTAR PASTE} (AMP)

From previous discussion, AMP is undoubtedly the main reason for the lower quality of RCA compared to NAs. More attention should be paid to monitor the effects of the AMP on the RCA properties and consider them in the concrete mix proportion design. Some scholars reported that the porous nature of the old mortar is responsible for the increased water absorption capacity, high permeability and decreased density and specific gravity of RCA. The high water demand of the crushed aggregates affects the workability of the fresh concrete, thereby that affects the mechanical properties of the concrete in the hardened state [10][11]. The presence of the old mortar makes the RCA a multiple phases material. Concrete made with natural and recycled aggregate contain more than two phases. The ITZs between old and new elements. Close inspection revealed in figure $2 \& 3$ that the interfacial transition zone (ITZ) between the AMP and the original aggregate has a lot of voids and micro-cracks which lead to a high tendency of 
cracking and reduction in the bond between the new mortar and the old mortar. Consequently, RCA concrete has lower strength and lower elasticity modulus compared to conventional concrete [12][13]

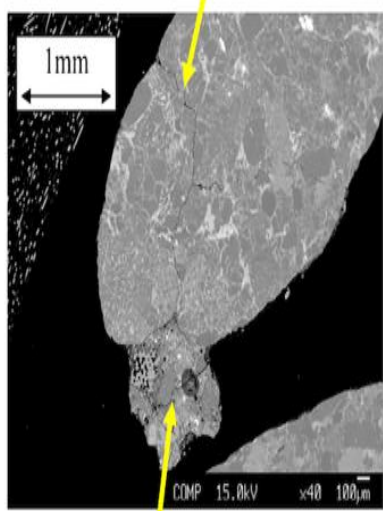

Cracks in original paste
Cracks in original aggregate
Voids in original paste

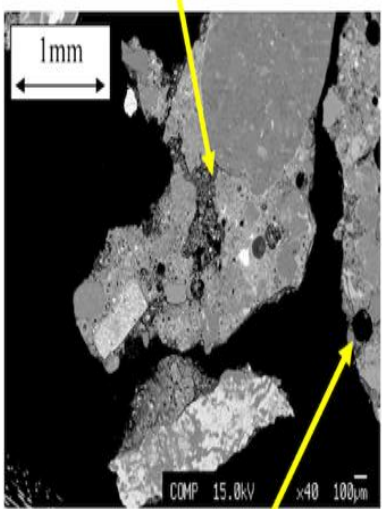

Pores in original paste
Fig -2:Grains of recycled fine aggregate crushed by a jaw crusher [14]

Moreover, as a consequence of the exposure of the old concrete to aggressive attacks during the previous exploitation, the AMP may contain harmful chemical substances. It is crucial to know if the original concrete contained potentially reactive compounds to avoid damaging reaction and durability problem.

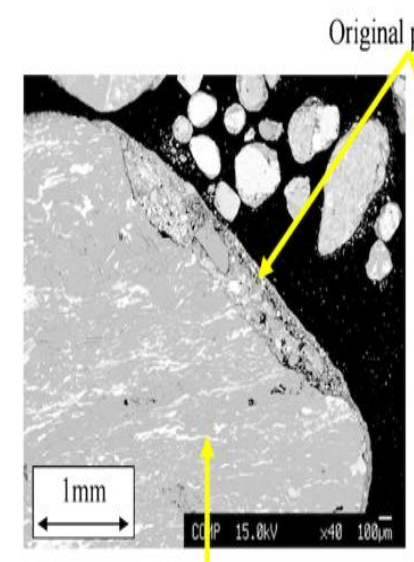

Original aggregate

(a)

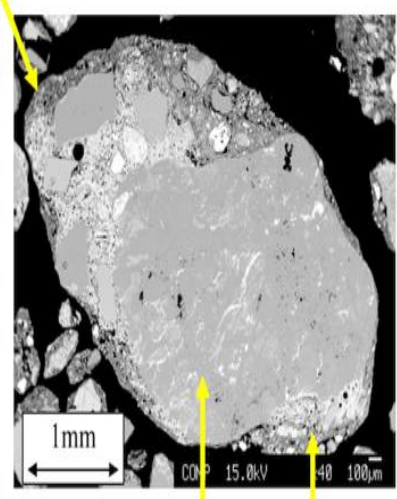

$\begin{array}{cc}\text { Original } & \text { Original } \\ \text { aggregate } & \text { paste }\end{array}$

(b)
Fig -3:Grains of recycled fine aggregate with brittle parts removed[14]

Based on its weakness plenty research have been done to improve the quality of the AMP. Results showed the advantageous effect of using mineral admixtures like fly ash, silica fume, and slag in the RAC concrete mix. Mineral admixtures use their strong filling effect and their pozzolanic properties to heal pores and cracks of the AMP. Mineral admixtures particles are much fine and can occupy the small voids in the outer layer of RCA. Pozzolanic reactions of mineral admixtures with $\mathrm{Ca}(\mathrm{OH}) 2$ produce a secondary C-S-H gel which strengthens the weak bond of RCA and other concrete's compounds [15][16][17].

\subsection{Increased Rate of Water Absorption}

As a direct consequence of the AMP, water absorption is one of the most marked differences between RCA and NAs. Almost all-available research in this area reported that RCA manifest higher water absorption compared to NAs. Many researchers concluded that the porous nature of this residual paste is the main reason behind this behavior [18]. The quantity of water available in the concrete mix is influenced by the ability of RCA to absorb water. Joseph et al. [19]reported that the water absorption capacity can reach $10 \%$ where as natural aggregate water absorption values less that $1 \%$. The high water absorption capacity of RCA should be taken into account as it can lead to shortage of water in the concrete mix, affecting the rheological properties of the freshly mixed concrete and the mechanical properties and the durability of hardened concrete. The absorption rate is different for various RCA based on its source of extraction and hence, no standard form of instructions exists for the determination of required water quantity during mix design.

However, soaking RCA for a short time before the concrete mixing can help to overcome this issue [20]. But this method is not practical for concrete mass production or fine RCA's as kinetics of water absorption by RCA is fast in the early stages when aggregates get in contact with water.

\section{IMMINENT QUALITIES OF RAC}

The qualities of RAC are antigenic determinants for it's performance and durability and hence international laboratory specification codes often use a combination of performance \& prescriptive determining factors, such as workability, compressive strength, Split tensile strength, flexural strength and water- cement material ratio to describe concrete durability and performance. From above discussion, it is obvious that concrete made with RCA will behave differently compared to conventional concrete due to some imminent qualities. Therefore, water Absorption, workability, compressive strength, flexural Strength and tensile split are described as Imminent qualities of RAC.

\subsection{Reduced Workability and Challenge of Mix Design for RAC}

RCA particles are irregular, with rough-textured, angular shape, cracked and porous surface. These RCA particles characteristics hugely affect the workability of the fresh concrete. RCA have relatively high water absorption and subsequently absorb a portion of the water available in the concrete mix, which leads to a shortage of water in the mix. Therefore, it is absolutely important to thoroughly understand the influence of RCA on the concrete structure during the design of the RCA concrete mix proportion. The workability of the fresh concrete decreases proportionally with the increase of RCA. Parekh et al. [21]observed that 
when the substitution ratio of NAs by RCA is considerable (50\% or more), the RCA concrete had poor cohesiveness compared to the concrete made with only virgin aggregate. As a consequence of this lack of cohesiveness, the integrity and homogeneity of the fresh concrete during casting were affected, which in turn affected the durability and mechanical properties of the hardened concrete. A presaturation technique, which consists in immersing RCA in water before being used in the concrete mix, was adopted by Julia Garcia-Gonzalez et al. [20]. The Results obtained proved that by immersing RCA in water before the mixing, the consistency of the fresh concrete with RCA is improved. Nonetheless, this technique leads to a loss in compressive strength because it needs more water in the mix and it is unfeasible with recycled fine aggregate [22]. Mirjana Malesev et. al.[23] added extra water in concrete mix to get the desired workability of concrete with RCA. The additional water was determined on the basis of the water absorption capacity of the RCA. The workability was found to be approximately the same after $30 \mathrm{~min}$. Sandrine et al. [24] used a different approach to optimize the workability. Super-plasticizers were used to improve the workability of concrete mix with a partial or total substitution of NAs by RCA. They observed that the compressive strength was enhanced as a result of better rheological properties.

\subsection{Poor Mechanical Performance}

The mechanical properties of concrete prepared with RCA have been extensively studied in recent years. Normally, the use of RCA as a replacement of NA affects negatively the mechanical performance of the concrete. Many researchers reported that the elasticity and strength characteristics values of RCA concrete are lower compared with conventional concrete. Generally speaking, the use of RCAs leads to a severe reduction of the compressive strength, tensile strength, flexural strength, elasticity of modulus, etc. The following discussion will focus on the compressive and flexural strength of RCA concrete.

\subsubsection{Compressive Strength}

The compressive strength can be considered as the most important engineering property of a concrete. Therefore, many scholars have turned their focus on the compressive strength of concrete made with RCA. In general, research findings showed that the use of RCAs in concrete leads to severe reduction in compressive strength. The extent of this loss depends on different factors, for instance, the replacement ratio of NAs by RCAs, concrete mix proportion (water to cement ratio), sources and quality of RCAs, the use of chemical or mineral admixtures.

Replacement ratio level: In most cases the incorporation of RCA in the concrete result in the loss of compressive strength. According to experimental practice, a full substitution of NA with RCA can lead to the lowering of the compression strength up to $25 \%$ [25][26]. It is important to notice that several researchers reported that NA can be substituted by RCA up $25 \%$ without major consequences on the compressive strength [23][26].
Influence of the strength of the original concrete: Mirjana et. al. [27]stated that the influence of RCAs on the compressive strength primarily depends on the strength of the original concrete. If RCAs are obtained from concrete with higher compressive strength than the targeted compressive strength, it is possible to produce recycled concrete with almost equal or even higher compressive strength than concrete produced with only virgin aggregates [23]

Beneficial effect of admixtures: The use of chemical additives like water reducing agent, or supplement cementitious material such as fly ash, silica fume, etc. has been proven to enhance the compressive strength [28][29].

\subsubsection{Flexural Strength}

Chen $\mathrm{Z}$ et. al [30]proved by experimental research that the increment of recycled coarse aggregate replacement rate leads to decrement of beam rigidity which results in increased beam deflection. This scenario renders RAC less fit for high tensile stress compared to ordinary concrete. Meanwhile, RA extracted from good quality concrete without impurities possesses higher strength than normal aggregates as investigated by K. Usha Nandhini et.al. [31].

\subsection{Inadequate Level of Durability}

Concrete structures are designed to not only ensure safety and serviceability function; they also need to keep sufficient ability to resist deterioration under a long-term service. Carbonation penetrations, chloride conductivity, alkali silica reaction, freeze thawing resistance and sulfate attack resistances are some of the concrete durability indicators parameters. The durability of a concrete is greatlyinfluenced by its pore structure and its transport properties. We are aware that concrete with RCA have high porosity and high permeability, which make it more vulnerable to the aggressive attack from the environment to which it is exposed to. Research efforts showed that the use of mineral admixtures such as fly ash, silica fume and slag as replacement for cement or a supplement to it can ameliorate concrete durability due to densification of pore structure and reduction of permeability.

\subsubsection{Corrosion}

The Chloride penetration is together with the carbonation, the principal reasons of the reinforcement depassivation and thereby of the reinforcement corrosion. In numerous studies, the effect of RCA on the Chloride penetration and carbonation resistance has been investigated. Results showed that with the increase of RCA amount, the chloride penetration increase accordingly. Similarly, the increase of RCA content resulted in lower carbonation resistance.

\subsubsection{Sulfate Attack}

RAC naturally is more permeable and has a lower density than conventional concrete and therefore, sulfates attack on RAC could be more aggressive than on conventional concrete. It is necessary to know the characteristics of RAC 
exposed to sulfates, so that necessary precautions can be taken to minimize the deterioration to insignificant levels. The cementing matrix of RAC is advantageous for easy penetration of sulphate ions towards and within concrete. Also, high formation rate of gypsum during the pozzolanic reaction due to plenteous availability of calcium hydroxide $[\mathrm{Ca}(\mathrm{OH})]$ in $\mathrm{RAC}$.

\subsubsection{Freezing and Thawing Resistance}

Akinkurolere Olufunke Olanike [32] observed a reduction in freeze-thaw resistance due to the saturation of the aggregates during the test. However, RCA concrete with lower water binder ratio exhibited better performance of freeze-thaw durability.

\subsubsection{Akali-Silica Reaction (ASR)}

In addition, RCA may have been already contaminated by harmful chemical substances as a consequence of the exposure of the old concrete to aggressive attacks during the previous exploitation. For instance, it is crucial to know the content of potentially reactive aggregates in the old concrete and possible continued alkali silica reaction (ASR) so as to avoid the development of ASR in the new concrete containing RCA.

\section{PERFORMANCE ENHANCEMENT FOR FUTURE RCA}

A large number of researches have been directed towards the utilization of dumped materials. To increase the performance and durability of the concrete made with recycled concrete aggregates, admixture \& fiber can be used.

\subsection{Admixtures}

Chemical admixtures are added to concrete in very small amounts mainly for air entrainment, reduction of water or cement content, plasticizing of fresh concrete mixtures or to control the setting time of concrete. The admixture increases the workability of the concrete at same water cement ratio. Fly-ash and silica fume contribute in increase the resistance of recycled aggregate concrete to sulfate attack meanwhile silica fume contribute significantly in increase the steel corrosion resistance, due to cementing matrix densification and pore refinement [30]. Compressive strength loss of concretes containing recycled aggregate is less than the concretes containing natural aggregate at early age due to silica fumes usage. Also, water absorption of concretes containing the recycled aggregates with silica fumes is reduced significantly especially at later ages[29]. Larbi Belagraa [28] reported that the recycled aggregate concrete shows the same performance compared to normal concrete for an admixture optimal dosage of $1.5 \%$.

\subsection{Fibres and Polymer Treatments}

Fibres increase tensile \& flexural strength of the concrete. Many researchers like [33][34][35][36] confirmed that, addition of fibre content in RC is only influential on flexural and splitting tensile strength but the aggregate type influences the compressive strength. Adding fibre to concrete increases cracking resistance because the fibre bridges the gap between the adjacent surfaces of existing micro-cracks, delays crack formation, and limits crack propagation.[37]. On the other hand, there is a positive effect induced by polymer treatments on water absorption capacity of RCA. Polymer treatments emphasize the formation of polymeric film in pore network and allows the significant reduction of water absorption capacity and consequently makes it efficient and resistant in alkali environment.[38].

\subsection{Pre-washing \& Surface Treatment}

Also it is expected that the efforts to surface-treat \& wash recycled aggregate with acid will contributes effectively to the strength and performance of RAC. Sallehan Ismail [39] conducted a study of RCA surface-treated in calcium silicate solution and observed that the calcium silicate provides a coating layer on the RCA and functions as a microfiller that can refill and treat the cracks and pores on the RCA surface. In addition, the calcium silicate particles on the RCA surface causes a pozzolanic reaction during concrete hardening that could improve the microstructure of concrete by strengthening the bonds between RCA and the cement paste and consequently further enhancing the compressive strength of concrete.

\section{CONCLUSION}

Recycling concrete is an important step towards eco-friendly construction practices. It reduces the amount of construction and demolition wastes, and at the same time, it lessens the depletion of natural resources. However, the use of recycled concrete aggregates leads to the loss of strength and less resistance to deterioration mechanism. These bad behaviors can be resolved through effective removal of the adhered mortar paste attached on recycled aggregates which consequently strengthens RAC characteristics. Also incorporating supplement admixtures materials such as fly ash, silica fume, etc. and addition of fibres can enhance the mechanical properties considering an appropriate concrete mix design. Therefore, RCA is a potential tool for sustaining green environment and as well as providing adequate level of structural performance in engineering applications if the suggested measures are considered.

\section{ACKNOWLEDGEMENT}

I would like to express my most profound appreciation to the Ministry of Education of Burundi for the financial assistance that made my research project successful. I am also thankful to the School of Civil Engineering and Architecture of Zhejiang University of Science and Technology for all the resources they made available to facilitate my research study. Finally, we commend Engineering Simulation and Data Management(ESDM) team for its support. 


\section{REFERENCES}

[1] The Freedomia Group World Construction Aggregates - Demand and Sales Forecasts, Market Share, Market Size, Market Leaders.

[2] Tam V and Lu W 2016 Construction Waste Management Profiles, Practices, and Performance: A Cross-Jurisdictional Analysis in Four Countries Sustainability8 190

[3] Wang C, Li Q, Zhu J, Gao W, Shan X, Song J and Ding X 2017 Formation of the 2015 Shenzhen landslide as observed by SAR shape-from-shading Sci. Rep.7 43351

[4] Pepe M 2015 A Conceptual Model for Designing Recycled Aggregate Concrete for Structural Applications (Cham: Springer International Publishing)

[5] Akbarnezhad A, Ong K C G, Zhang M H, Tam C T and Foo T W J 2011 Microwave-assisted beneficiation of recycled concrete aggregates Constr. Build. Mater. 25 3469-79

[6] Pepe M, Toledo Filho R D, Koenders E A B and Martinelli E 2014 Alternative processing procedures for recycled aggregates in structural concrete Constr. Build. Mater.69 124-32

[7] Al-Bayati H K A, Das P K, Tighe S L and Baaj H 2016 Evaluation of various treatment methods for enhancing the physical and morphological properties of coarse recycled concrete aggregate Constr. Build. Mater.112 284-98

[8] Güneyisi E, Gesoğlu M, Algın Z and Yazıcı H 2014 Effect of surface treatment methods on the properties of self-compacting concrete with recycled aggregates Constr. Build. Mater.64 172-83

[9] Tam V W Y, Tam C M and Le K N 2007 Removal of cement mortar remains from recycled aggregate using pre-soaking approaches Resour. Conserv. Recycl.50 82-101

[10] Ismail S and Ramli M 2013 Engineering properties of treated recycled concrete aggregate (RCA) for structural applications Constr. Build. Mater.44 46476

[11] Mefteh H, Kebaïli O, Oucief H, Berredjem L and Arabi N 2013 Influence of moisture conditioning of recycled aggregates on the properties of fresh and hardened concrete J. Clean. Prod.54 282-8

[12] Etse G, Caggiano A, Etse G and Caggiano A 2012 Multiscale failure analysis of fiber reinforced concrete based on a discrete crack model Author' $\mathrm{s}$ personal copy

[13] Liu Q, Xiao J and Sun Z 2011 Experimental study on the failure mechanism of recycled concrete Cem. Concr. Res.41 1050-7

[14] Ogawa H and Nawa T 2012 Improving the Quality of Recycled Fine Aggregate by Selective Removal of Brittle Defects J. Adv. Concr. Technol.10 395-410

[15] Jiu-su L I, Han-ning $X$ and Jian-qing G 2008 Granular Effect of Fly Ash Repairs Damage of 13 177-80

[16] Abd Elhakam A, Mohamed A E and Awad E 2012 Influence of self-healing, mixing method and adding silica fume on mechanical properties of recycled aggregates concrete Constr. Build. Mater.35 421-7

[17] Hai-long W, Jun-jie W, Xiao-yan S U N and Weiliang J I N 2013 Improving performance of recycled aggregate concrete with superfine pozzolanic powders 3715-6

[18] de Juan M S and Gutiérrez P A 2009 Study on the influence of attached mortar content on the properties of recycled concrete aggregate Constr. Build. Mater.23 872-7

[19] Joseph M, Boehme L, Sierens Z and Vandewalle L 2015 Water absorption variability of recycled concrete aggregates Mag. Concr. Res.67 592-7

[20] García-González J, Rodríguez-Robles D, Juan-Valdés A, Pozo J M M del and Guerra-Romero M I 2014 Pre-saturation technique of the recycled aggregates: Solution to the water absorption drawback in the recycled concrete manufacture Materials (Basel).7 6224-36

[21] Parekh D N and Modhera C D 2012 Workability Study for Recycled Aggregates 2 1040-4

[22] Rodrigues F, Evangelista L and Brito J de 2013 A new method to determine the density and water absorption of fine recycled aggregates Mater. Res.16 1045-51

[23] Malešev M, Radonjanin V and Marinković S 2010 Recycled concrete as aggregate for structural concrete production Sustainability2 1204-25

[24] Sandrine Braymand, Pierre François, Françoise Feugeas and Christophe Fond 2015 Rheological Properties of Recycled Aggregate Concrete Using Superplasticizers J. Civ. Eng. Archit.9 591-7

[25] Katz A 2003 Properties of concrete made with recycled aggregate from partially hydrated old concrete Cem. Concr. Res.33 703-11

[26] Etxeberria M, Vázquez E, Marí A and Barra M 2007 Influence of amount of recycled coarse aggregates and production process on properties of recycled aggregate concrete Cem. Concr. Res.37 735-42

[27] Rashwan M S and Abourizk S 1997 The properties of recycled aggregate concrete Concr. Int. v. 192 56-60

[28] Belagraa L and Beddar M 2013 Study of the Mechanical Performance of a Recycled Aggregate Concrete with Admixture Addition Open J. Civ. Eng.3 99-103

[29] Çakır Ö and Sofyanlı Ö Ö 2015 Influence of silica fume on mechanical and physical properties of recycled aggregate concrete HBRC J.11 157-66

[30] Corral-Higuera R, Arredondo-Rea S P, Neri-Flores M A, Gómez-Soberón $\mathrm{J}$ M, Almeraya Calderón $\mathrm{F}$, Castorena-González J $\mathrm{H}$ and Almaral-Sánchez J L 2011 Sulfate attack and reinforcement corrosion in concrete with recycled concrete aggregates and supplementary cementing materials Int. J. Electrochem. Sci.6 613-21

[31] Nandhini K U, Jayakumar S and Kothandaraman S 2016 Flexural Strength Properties of Recycled 5 6-11

[32] Olanike A O 2014 Experimental Investigation into the Freeze-Thaw Resistance of Concrete Using Recycled Concrete Aggregates and Admixtures Civ. Eng. Archit.2 176-80 
[33] Vodicka J and Vytlačilová V 2016 Examples of Use of FRC with Recycled Concrete in Structures Procedia Eng.151 337-44

[34] Spadea G and Bencardino F 1997 Behavior of fiberreinforced concrete beams under cyclic loading $\mathrm{J}$. Struct. Eng.123 660-8

[35] Carneiro J A, Lima P R L, Leite M B and Toledo Filho R D 2014 Compressive stress-strain behavior of steel fiber reinforced-recycled aggregate concrete Cem. Concr. Compos.46 65-72

[36] Akça K R, Çakır Ö and Ipek M 2015 Properties of fiber reinforced concrete using recycled aggregates Constr. Build. Mater.98 620-30

[37] Şahin Y and Köksal F 2011 The influences of matrix and steel fibre tensile strengths on the fracture energy of high-strength concrete Constr. Build. Mater.25 1801-6

[38] Spaeth V and Djerbi Tegguer A 2013 Improvement of recycled concrete aggregate properties by polymer treatments Int. J. Sustain. Built Environ.2 143-52

[39] Ismail S and Ramli M 2013 Effect surface treatment of recycled concrete aggregate on properties of fresh and hardened concrete 2013 IEEE Business Engineering and Industrial Applications Colloquium (BEIAC) (IEEE) pp 651-6

\section{BIOGRAPHIES}

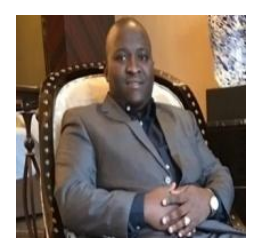

Tresor Ntaryamira, MSc. Civil Engineering, Zhejiang University of Science and Technology, China and BSc. Civil Engineering, Tonji University, China.

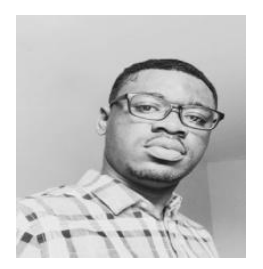

Anthony Quansah, MSc. Civil Engineering, Zhejiang Uni.Sci.\& Tech, China and BSc. Civil Engineering, K.N. Uni.Sci \& Tech, Ghana. Senior Editor, International Journal of Sciences (ijsciences), S.M. ASCE, American Society of Civil Eng. M. ICE, Institue of

Civil Engineers, U.K. \& Member of ResearchGate Community

Zhang Yunlian, Ph.D. Tongji University, China, 2006 \& M.S. Hangzhou University, China, 1993. B.S. Hangzhou University, China, 1990 